\title{
THIN- LAYER DRYING OF DICED CASSAVA ROOTS
}

\author{
Kajuna S.T.A.R. ${ }^{1}{ }^{*}$, V.C.K. Silayo ${ }^{2}$, A. Mkenda $^{3}$ and P.J.J. Makungu ${ }^{1}$ \\ Department of Agricultural Engineering and Land Planning, \\ Sokoine University of Agriculture,P.O. Box 3179, Morogoro, Tanzania. \\ e-mail:kajuna@suanet.ac.tz, skajuna@yahoo.com
}

\begin{abstract}
Fresh cassava (Manihot spp) roots were obtained from a farm and used in this study. They were peeled and diced using a special dicing machine into cubes of side $0.5 \mathrm{~cm}$. The cubes were dried in thin layers (one to three layers) in a drier that was specifically designed and fabricated in the Department of Agricultural Engineering and Land Planning, Morogoro, Tanzania for the purpose. The drier had a motor driven fan, a heater and a tray chamber, with thermometers for determining entry and exit temperature (dry and wet bulb) conditions of the air. The input variables were: depth of thin layer $(0.5,1.0$ and $1.5 \mathrm{~cm})$, drying temperature of the air $\left(55\right.$ and $65^{\circ} \mathrm{C}$ ) and drying time (from 0 min until the sample attained equilibrium, at intervals of $25 \mathrm{~min}$ ). The response variable was the moisture content of the cassava cubes. Weather conditions during the experiments were also monitored. A parallel sun drying experiment was carried out to compare thin layer drying on the sun and thin layer drying in the fabricated dryer. For the fresh cassava that was used in the experiments, a duplicate sample was placed in an oven at $75^{\circ} \mathrm{C}$ for 7 hours to determine the initial moisture content. The results indicated that the average moisture content of fresh cassava roots was about 75.4 $\%(w . b$.$) . Both temperature and depth of layers were found to affect the drying characteristics of$ cassava cubes, with single layer and higher drying temperature giving faster approaches to equilibrium moisture content. Comparing sun drying of one layer at an average temperature of $25^{\circ} \mathrm{C}$ with artificial drying at the above named temperatures, it was found that sun drying took 2 to 3 days to reduce the moisture content to Equilibrium Moisture Content (EMC), while this was achieved within $150 \mathrm{~min}$ and $125 \mathrm{~min}$ with artificial drying at $55^{\circ} \mathrm{C}$ and $65{ }^{\circ} \mathrm{C}$ respectively. The generally accepted thin layer drying equations were fitted to the drying data of cassava cubes, and the Page model was found to agree with the drying data of one, two and three layers with high accuracy for artifial drying, but not for sundrying. The exponential model only agreed accurately with drying of one layer.
\end{abstract}

KEY WORDS: Cassava cubes, Thin layer drying, Temperature, Moisture content

\section{INTRODUCTION}

Cassava (Manihot esculenta) is the third most important staple food in the tropics, after rice and maize (Odogola, 1988). It is believed to provide $37 \%$ of the calorie requirement in Africa, and $12 \%$ and $7 \%$ in Latin America and Asia respectively (Odogola, 1988). In Africa, Tanzania is the third largest producer of cassava, next to the Democratic Republic of Congo and Nigeria (FAO, 1985; CIAT, 1993, quoted by Mlingi, 1995). However, in Tanzania, the crop is only important in half of the country's twenty regions.

In Tanzania, cassava is maily regarded as famine security food. It is widely consumed as a snack when roasted, boiled and eaten as a main meal, or milled into flour and prepared into stiff porridge (ugali). The latter may be either a pure flour or a composite flour where it is mixed with maize of sorghum (Bangu et al., 1998).

Among the problems limiting utilization and consumption of cassava is the rapid spoilage of the roots after harvesting (Nghiem, 1991). This problem can be minimized by cold storage or processing in to more stable products. Cassava roots stored at temperature and $\mathrm{RH}$ of $13^{\circ} \mathrm{C}$ and $85-90 \%$ respectively can last for a maximum of 2 months and 5-6 months when stored at temperature and RH of $0-2{ }^{\circ} \mathrm{C}$ and 85 - 90\%, respectively (NRI, 1994). 
In most cases, cold storage is not economically feasible, hence processing remains the best alternative towards improving availability of the crop during off-season period.

The most common processing methods are direct sundrying of peeled roots for days in to a storable product, known as makopa (Mlingi, 1985). Another method is fermentation of peeled roots by soaking in water for several days. A third method is fermentation of peeled root pieces in covered heaps to enhance mould growth desired to impart special characteristics to the end product after drying. The different dried products can then be stored or milled into flour to produce stiff porridge. However, due to weather uncertainities, sometimes drying can not proceed quickly enough. This may result in growth of undesirable moulds such as Aspergilus flavus that produces aflatoxins.

Quick drying of cassava is advantageous in the sence that the risks of contamination and mould growth are minimized. Moreover, drying reduces the levels of cyanogenic glucosides which is a potential toxin naturally present in cassava. The established 17 days of sun-drying of longitudinally split roots only reduces cyanogenic glucosides to $27-37 \%$, leaving more than $100 \mathrm{mg} \mathrm{HCN}$ equivalent per kg dry weight of flour, that is ten times the safe level set by FAO/WHO (Mlingi, 1995).

\section{THEORY}

Where heated air air is used as drying medium, the primary factor influencing the rate of drying is temperature (Yunfei and Morey, 1987). In a study by Pathak et al., (1991), the effect of drying temperature on thin-layer drying was high, followed by initial moisture content, air velocity and relative humidity as the least factor that warranted its exclusion from consideration in the evaluation of thin-layer drying rate of rapeseed. It has been reported, that drying is independent of air velocity in the range of 0.15 to $0.81 \mathrm{~m} / \mathrm{s}$, but depends sharply on the drying temperature of the air from 21.1 to $76.7^{\circ} \mathrm{C}$ (Simmonds et al., 1953, quoted by Sun and Woods, 1994).

In drying of thin-layers of agricultural crops, the Page equation has been used extensively. It was successfully used to describe drying characteristics of American Ginseng (Yunfei and Morey, 1987), oilseeds such as sunflower (Yunfei et al., 1987). The equation is empirical, and is given as:

$$
M R=\frac{M-M_{e}}{M_{o}-M_{e}}=\operatorname{Exp}\left(-K t^{N}\right)
$$

where MR = Moisture ratio

Mo = initial moisture content $(\% \mathrm{db})$

$$
\begin{array}{ll}
\mathrm{Me} & =\text { equilibrium moisture content }(\% \mathrm{db}) \\
\mathrm{M} & =\text { moisture content at time } \mathrm{t}(\% \mathrm{db}) \\
\mathrm{t} & =\text { drying time }(\mathrm{hr}) \\
\mathrm{K} \text { and } \mathrm{N} & =\text { drying constants. }
\end{array}
$$

The above equation is a modification of the theoretical model, known as the exponential or the Newtonian model (Sun and Woods, 1994). The model is described as (Nellist, 1976; Colson and Young, 1990; Pattey et al., 1988; Crisp and Woods, 1994)

$$
\frac{d M}{d t}=-k\left(M-M_{e}\right)
$$

where $k=$ drying constant.

Differentiating equation 2 gives (Nellist, 1976; Sun and Woods, 1994)

$$
M R=\frac{M-M_{e}}{M_{o}-M_{e}}=\operatorname{Exp}(-k t)
$$

Equation 3 assumes that resistance to moisture movement and thus gradients within the material are negligible (Colson and Young, 1990). At constant temperature, pressure and hmidity, this equation is valid if drying is characterized by "falling-rate" regime (Nellist, 1976) which is a characteristic of drying of low moisture content products such as grains. As quoted in Sun and Woods (1994), this model has been successfuly used for barley (Sharp, 1982; Bruce, 1985), wheat (Simmonds et al., 1953), paddy (Kachru et al., 1980), and shelled corn (Westerman et al., 1973). The drying constants in thin-layer drying equations vary with temperature (Yunfei and Morey, 1987; Verma et al., 1985). In the work of Misra and Brooker (1980) on yellow corn, the initial moisture content was also found to affect the drying rate or constants.

\section{OBJECTIVE}

The objective of this work was to determine the drying characteristics of diced cassava roots in an artificial dryer at temperatures higher than the ambient temperatures. The data obtained from thin-layer drying of the cubes would be fitted to the generally accepted thin-layer drying models (equations $1 \& 3$ ) to predict the drying characterics.

\section{METHODOLOGY}

\section{The Drying Equipment}

A dryer (Figure 1) was designed and fabricated at the Department of Agricultural Engineering and Land Planning at Sokoine University of Agriculture, Morogoro, Tanzania. 


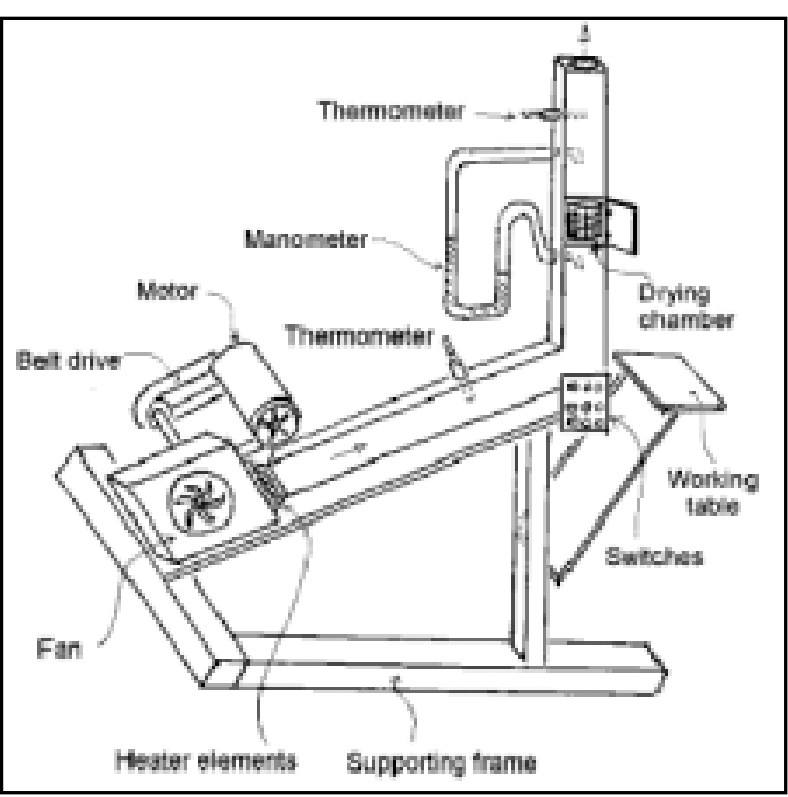

Figure 1. Schematic representation of the thin-layer drying equipement.

It consisted of a constant speed motor $(0.5 \mathrm{hp})$ for driving a blower; a centrifugal blower (Type CNA-250/R, NR 84015141-001, Nordisk Ventilator, Denmark); heating chamber, consisting of two heater elements for heating air, and a circular column for leading air to and from the drying tray. The column was insulated with foam material and enclosed in a $30 \mathrm{~cm}$ square column to minimize heat loss. Other components of the dryer were: the perforated drying tray (10 cm diameter) for holding the sample to be dried; a pair of thermometers, for recording temperature of the inlet and outlet air; and a manometer for recording loss in head.

\section{Preparation of the Sample.}

Freshly harvested cassava roots (Manihot spp) were obtained from a neighbouring farm and sent to the laboratory for the study. They were peeled, and part of the meet removed from one side to create a flat surface. The root was laid by the flat surface onto the board of a slicing machine, schematized in Figure 2, which was also designed and manufactured for the purpose at the Sokoine University of Agriculture.

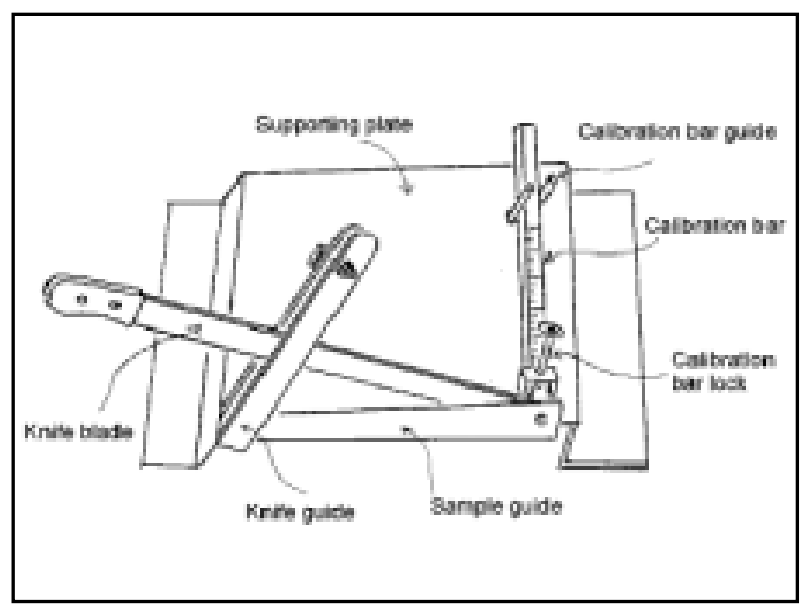

Figure 2. Schematic representation of the slicing machine.

The machine was calibrated for slicing $5 \mathrm{~mm}$ thick slices. The root was then sliced into $5 \mathrm{~mm}$ thin rectangular slices, and then re-sliced to produce cubes of $5 \mathrm{~mm}$ size .

\section{Drying Procedure}

Before drying, the heater of the dryer was switched on and the blower allowed to run for about 30 minutes to allow the heated air to stabilize at the desired temperature. Two temperature settings, namely, 55 and $65^{\circ} \mathrm{C}$ were used for the drying work. Air velocity was measured by an air flow meter (Type 5 manometer, Air flow Developments Ltd, High Wycombe, UK). Dry-bulb and wet-bulb temperatures of ambient air were measured by a sling psychrometer and the data were interpretted into relative humidity using a psychrometric chart at atmospheric pressure.

At the above temperatures, cassava cubes were dried in the dryer in one layer $(5 \mathrm{~mm})$, two layers $(10 \mathrm{~mm})$ and three layers $(15 \mathrm{~mm})$, each weighing $100 \mathrm{~g}, 200 \mathrm{~g}$, and $300 \mathrm{~g}$ respectively, and forming a total of six runs. The runs were replicated three times. The drying process was allowed to continue until no more weight loss was recorded between two successive readings. The control was a parallel sundrying experiment of the same amount of material at ambient conditions. However, this was only done parallel to the $55^{\circ} \mathrm{C}$. Concurrent with each drying run, three samples of cubes, about $100 \mathrm{~g}$ each were parallel dried in a ventilated oven ( CARBOLITE model NR-30F, Fison way, Thetford, Norfolk, England) at a temperature of $75^{\circ} \mathrm{C}$ for six hours to determine the initial moisture content.

The drying response variable measured was weight loss at time intervals of 25 minutes. This involved quick withdrawal of material from the dryer set-up and quick weighing using a laboratory balance (Sartarius Universal, 
Model U6100-A, GMBH, Gottingen, Germany). The sample was quickly put back to continue with drying. Based on the initial moisture content from oven drying, the weight loss was used to calculate the moisture content using the equation of Silayo (1995), given as

$M_{t}=\frac{M_{i} m_{i}-w_{l}}{m_{i}-w_{l}}$

Where $M_{t}=$ m.c. at time t, $(\%$ w.b) $M_{i}=$ initial m.c, $(\% \mathrm{w} . \mathrm{b})$

$m_{i}=$ initial weight, $(\mathrm{g})$

$w_{l}=$ weight loss at time $\mathrm{t},(\mathrm{g})$

The moisture content was converted to moisture ratio (MR) using the non-exponential part of equations (1) and (3).

\section{RESULTS AND DISCUSSION}

The drying air velocity was found to be $0.67 \mathrm{~m} / \mathrm{s}\left(0.02 \mathrm{~m}^{3} /\right.$ $\mathrm{s}$ ), which was within the range that does not affect the drying rate (Simmonds et al., 1953 quoted by Sun and Woods, 1994). The relative humidity of air ranged between 68 and $85 \%$.

The moisture content of freshly harvested tubers was found to be $75.4 \%$ wet basis. Literature reports a lower value of $60 \%$ (Nghiem, 1991) and 62.5\% wet basis (Mlingi, 1995). The discrepancy could be attributed to the difference in species used, difference in locality and seasonality of the harvesting period (ie rainy or sunny seasons). In this case, the work was done immediately after the heavy rain season. The maturity of the root could be another reason for the higher moisture content in this study because experiene shows that as the roots of some varieties grow old in the soil, they tend to develop water-soaked tissues, especially around the pith. In this case, the roots tested were about two years old in the soil. Another reason which could have caused the difference in moisture content is the method used in the determination of the moisture content of which Nghiem (1991) is silent.

\section{Equilibrim Moisture Content (EMC)}

At the air temperature of $65^{\circ} \mathrm{C}$, the EMC of cubes was reached after 125,150 and 175 minutes for one, two and three layers respectively. This is indicated by moisture ratio (MR) of zero as presented in Figures 3, 4 and 5.

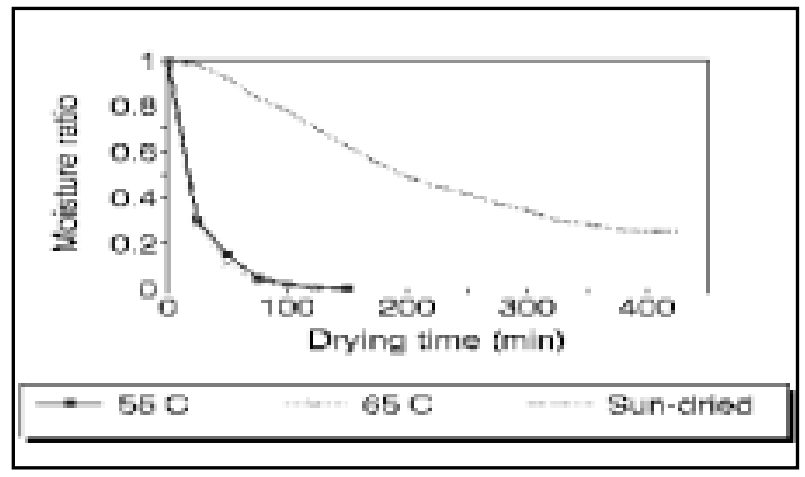

Figure 3. One layer drying of cassava cubes, showing change in moisture ratio with time at temperatures of $55,65{ }^{\circ} \mathrm{C}$ and sundrying.

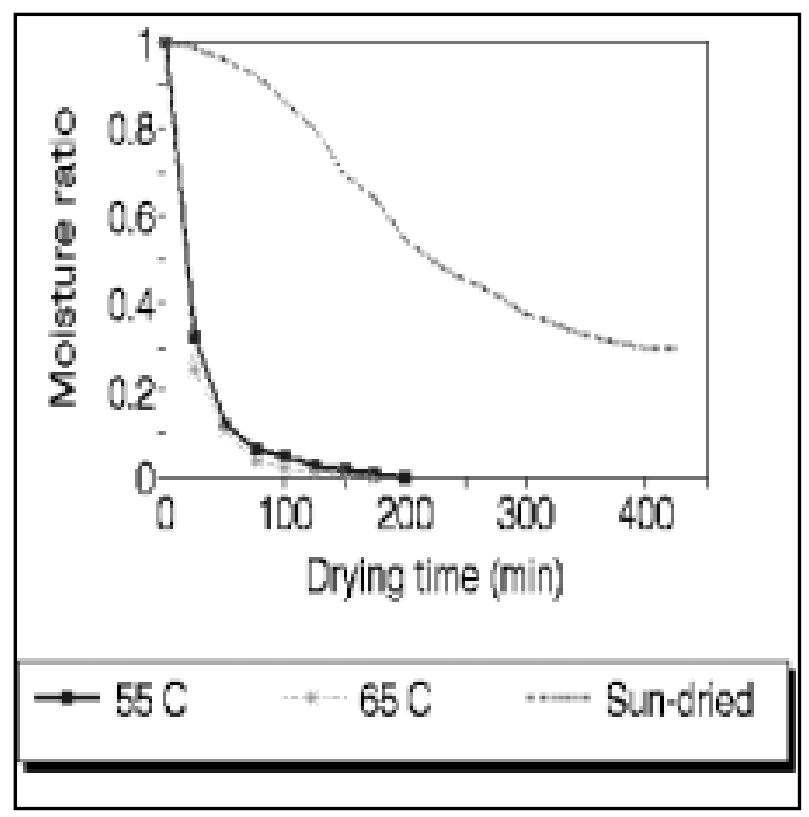

Figure 4. Two layer drying of cassava cubes at $55,65{ }^{\circ} \mathrm{C}$ and sundrying. 


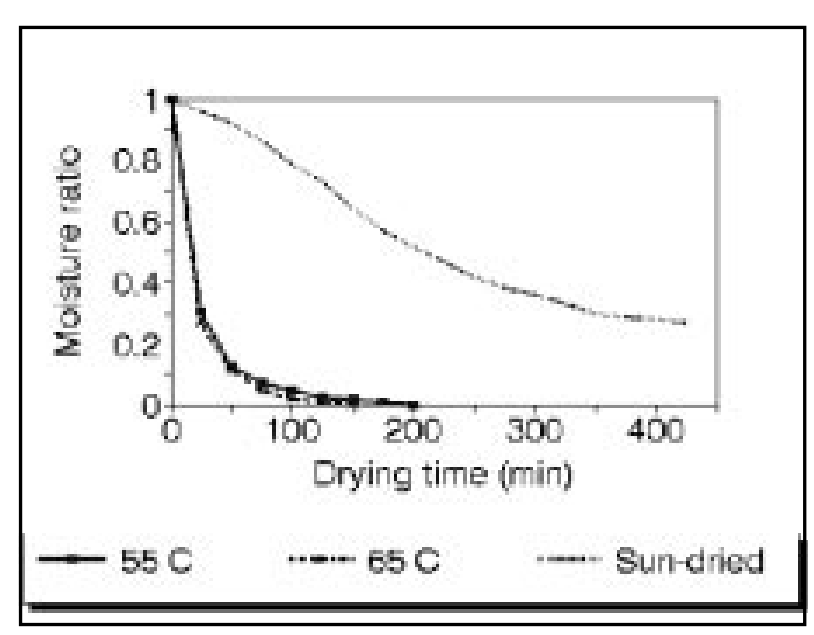

Figure 5. Three layer drying of cassava cubes at $55,65^{\circ} \mathrm{C}$ and sundrying.

The trend was almost the same at $55^{\circ} \mathrm{C}$ (Figures 3 to 5) where EMC of cubes was attained after 150 minutes for one layer and 200 minutes for both two and three layers. This was expected because experience shows that at high drying temperature, the drying rate is high and vice versa.

For the sun-drying trials, the EMC for the single layer was attained after 31 hours of continuous drying (day and night). However, this was a lot of time compared to heated air drying at $55^{\circ} \mathrm{C}$ and $65^{\circ} \mathrm{C}$. Sun-drying of two and three layers, took 2-3 days and by then the bottom cubes had started to be discoloured (deteriorate) even before the EMC was reached. For the ease of comparison only the Moisture Ratio (MR) obtained on the first day of sun drying were compared with MR obtained from heated air drying. These results show that heated air drying is superior to sundrying, even at moderate temperatures, for example $55^{\circ} \mathrm{C}$.

\section{Thin-Layer Dying Models}

Moisture ratio data obtained at air temperatures of 55 and $65^{\circ} \mathrm{C}$ for one layer, two layers and three layers of cassava cubes were fitted into both the Page (equation 1) and the exponential (equation 2) thin-layer drying models. From the results of this study, the exponential model was modified to take the form (Verma et al., 1985)

$$
M R=A \exp (-K t)
$$

The constants for equation 5 and regression coefficients for one, two and three layers are presented in Table 1.
Table 1.Constants and regression coefficints for the expnential model

\begin{tabular}{|c|c|c|c|c|c|c|}
\hline \multicolumn{7}{|c|}{ Temperature of the air $\left({ }^{\circ} \mathrm{C}\right)$} \\
\hline & \multicolumn{3}{|c|}{55} & \multicolumn{3}{|c|}{65} \\
\hline & 1 layer & 2 layers & 3 lay ers & 1 layer & 2 layers & 3 lay ers \\
\hline$\overline{\mathrm{A}}$ & 0.991 & 0.6573 & 0.6346 & 0.9490 & 0.7766 & 0.6447 \\
\hline K & -0.041 & -0.0264 & -0.026 & -0.045 & -0.0361 & -0.0327 \\
\hline$r^{2}$ & 0.993 & 0.975 & 0.973 & 0.999 & 0.990 & 0.974 \\
\hline
\end{tabular}

$\mathrm{A}=0.8544, \quad \mathrm{k}=-0.0021, \quad \mathrm{r}^{2}=0.856$

In the study of Verma et al., (1985) the constant "A" was used as a shape factor. But in this study, "A" was used to show the degree of fitness of the exponential model on top of the regression coefficient.

For one layer, deviation of the constant " $\mathrm{A}$ " from 1.0, which presents the ideal case of the exponential model is about $0.88 \%$ and $5.1 \%$ at air temperatures of 55 and $65^{\circ} \mathrm{C}$, respectively. For two layers the deviation increased to $34.3 \%$ and $22.3 \%$ at 55 and $65^{\circ} \mathrm{C}$ respectively, and 36.5 and $35.5 \%$ at the respective temperatures of 55 and $65^{\circ} \mathrm{C}$ for 3 layers. These show that the exponential model is best represented with the one/single layer drying data as in the case of grains. However, this is interesting since the model has been useful to single layer drying of low moisture content crops that exhibited "falling-rate" regime (Nellist, 1976) while in this case, , initial moisture content of cassava used was $75.4 \%$ wet basis. This was probably because in this work there was a short rapid drying period (Fig. 3-5), initially. For the two and three layers, the regression coefficients were found to be high $\left(r^{2}>0.9\right)$ which is an indication that the data obeyed an exponential law, but with decreasing approach to equilibrium moisture with increasing number of layers as shown by the values of $k$, parallel with decreasing values of "A" (Table 1).

However, for sun-drying of one layer, the deviation of " $A$ " from 1 was about $14.6 \%$ and a value of $r^{2}$ lower than the rest (0.856) was obtained. This was due to the fluctuating nature of solar radiation and the fact that the experiment was done continuously including day and night times.

The page model was linearized to form the equation (Pathak et al., 1991; Yunfei and Morey, 1987; Misra and Brooker, 1980; Yunfei et al., 1987)

$$
\ln (-\ln M R)=\ln K+N \ln t
$$


The constants for equation 6 and regression coefficients for one, two and three layers are presented in Table 2.

Table 2. Constants and regression coefficients for the Page model.

\begin{tabular}{|c|c|c|c|c|c|c|}
\hline \multicolumn{7}{|c|}{ Temperature of the air $\left({ }^{\circ} \mathrm{C}\right)$} \\
\hline & \multicolumn{3}{|c|}{55} & \multicolumn{3}{|c|}{65} \\
\hline & 1 layer & 2 layers & 3 layers & 1 layer & 2 layers & 3 layers \\
\hline $\bar{A}$ & 0.061 & 0.6573 & 0.1237 & 0.1217 & 0.0649 & 0.1047 \\
\hline K & 0.909 & -0.0264 & 0.7071 & 0.7087 & 0.9172 & 0.7826 \\
\hline$r^{2}$ & 0.983 & 0.975 & 0.990 & 0.991 & 0.996 & 0.999 \\
\hline
\end{tabular}

For sun-drying of one layer at $25^{\circ} \mathrm{C}$ :

$\mathrm{K}=0.0063, \quad \mathrm{~N}=0.8557, \quad \mathrm{r}^{2}=0.925$

The constant K shows a general increase with increasing number of layers, whereas $\mathrm{N}$ has shown a decreasing trend at one temperature $\left(55\right.$ or $\left.65^{\circ} \mathrm{C}\right)$. Moreover, both $\mathrm{K}$ and $\mathrm{N}$ values at $65^{\circ} \mathrm{C}$ were generally higher than those at $55^{\circ} \mathrm{C}$. For sun drying of one layer, these coefficients were different from the rest. However, the regression coefficients for this model were high $\left(r^{2}>0.9\right)$. From the empirical nature of the Page equation, the high $\mathrm{r}^{2}$ values are an indication that the model fits all the drying trials satisfactorily. Also, the coefficients $\mathrm{K}$ and $\mathrm{N}$ can not be fixed and their values depended very much on the prevailing experimental conditions $\mathrm{K}$ and $\mathrm{N}$.

\section{CONCLUSIONS}

The exponential (thin-layer drying) model was found to be suitalbe to describe drying of one layer of $5 \mathrm{~mm}$ cassava cubes at a temperature range of 55 and $65{ }^{\circ} \mathrm{C}$. On sundrying of one layer, the model represent the data poorly, but it is better than when used for two and three layers at these temperatures. The Page model can be fairly used for all the conditions similar to the ones that prevailed in this work, but with variable values of the constants.

\section{REFERENCES}

Bangu N.T.A., S.T.A.R. Kajuna and G.S. Mittal. 1998. Storage And Loss Moduli For Various Stiff Porridges. Proceedings of the Conference of The Tanzania Society Of Agricultural Engineers 17-19th November, 1998. TANESCO Kihonda, Morogoro, Tanzania. Vol. 8 page $99-108$.
Bruce D.M. 1985. Exposed Layer Barley Drying: Three Models Fitted To New Data Up To $150^{\circ} \mathrm{C}$. J. Agric. Engg. Res. 32:337-347.

CIAT. 1993. Cassava: The latest Facts About An Ancient Crop. Cali, Colombia.

Colson K.H. and J.H.Young. 1990. Two-Component ThinLayer Drying Model for Unshelled Peanuts. TRANS. ASAE, 33(1): 241-146.

Crisp J. and J.L. Woods. 1994. The Drying Properties of Rapeseed. J. Agric. Engg. Res. 57, 89-97.

FAO. 1985. Year Production Book, Rome, Italy.

Kachru R.P., T.P. Ojha and G.T. Kurp. 1980. Drying Characteristics of Indian Paddy Varieties. J. Agric. Engg. Res. 7:16-23.

Misra M.K., and D.B. Brooker. 1980. Thin-Layer Drying and Re-wetting Equations for Shelled Yellow Corn. TRANS. ASAE page 1254-1260.

Mlingi N.L.V.1995. Cassava Processinng and Dietary Cyanide Exposure inTanzania. PhD. Thesis, Faculty of Medicine, University of Uppsala, Sweeden.

Nellist M.E. 1976. Exposed Layer Drying of Ryegrass Seeds. J. Agric. Engg. Res. 21, 49-66

Nghiem Q. 1991. Development of Milksap-Free Cassava Half-Product in Vietnam. In Scott G, Wiersema S. And P.I. Ferguson (eds). Proceedings of the International workshop on Product Development for Root and Tuber Crops, Vol I, held in April 22-May 1, 1991 Vasays State College of Agric, (VISCA), Baybay, Leyte, Phillipines.

N.R.I. 1994. Manual for Horticultural Export Quality Assurance: Part II, page 8.3. Natural Resources Institute, Overseas Development Administration, London.

Odogola O.W. 1988. The Potential of Cassava As a Cash Crop For Small Holder Farmers Through The Development of Commercial and Industrial Production and Their Markets. Paper presented at the workshop on the contribution of cassava to food security in the member states of SADDC, Malawi, 28th Nov-1st Dec, 1988.

Pathak P.K., Y.C. Agrawal and B.P.N. Singh. 1991. ThinLayer Drying Model for Rapeseed. TRANS. ASAE, 34(6):2505-2508.

Pattey E., P. Savoie and P.A. Dube. 1988. The Effect of a Hay Tedder on The Field Drying Rate. Canadian Agricultural Engineering. Vol. 30(1):43-50.

Sharp J.R. 1982. A Review of Low-Temperature Drying Simulation Models. J.Agric. Engg. Res. 27:169-190.

Silayo V.C.K. 1995. Sundrying of Grains. Ph.D Thesis, University of Newcastle upon Tyne, UK. 
Sun D. and J.L Woods. 1994(a). Low-Temperature Moisture Transfer Characteristics of Barley: Thin-Layer Models and Equilibrium Isotherms. J.Agric. Engg. Res. 59:273283.

Sun D.W. and J.L. Woods. 1994(b). Low Temperature Moisture Transfer Characteristics of Wheat in Thin Layers. TRANS ASAE. Vol. 37(6):1919-1926.

Yunfei Li.R. and V. Morey. 1987. Thin-Layer Drying Rates and Quality of Cultivated American Ginseng. TRANS. ASAE. 30(3):842-847.

Yunfei Li.R., V. Morey and M. Afinrud.1987. Thin-Layer Drying Rates of Oilseed Sunflower. TRANS. ASAE. 30(4):1172-1175.

Verma L.R., R.A. Bucklin, J.B. Endan and F.T. Wratten. 1985. Effedts of Drying Air Parameters on Rice Drying Models. TRANS. ASAE, 296-301.

Westerman P.W, G.M. White and J.J. Ross. 1973. Relative Humidity Effect on The Hight Temperature Drying of Shelled Corn. TRANS. ASAE, 16: 1136-1139. 